\title{
When the Hospitalist Gets Hospitalized
}

\author{
Jay R. Lakhani, MD1
}

ABSTRACT

Author affiliations are

listed at the end of this

Hospitalists have a unique opportunity to provide a compassionate environment for article.

patients and families who are facing fear and uncertainty. Recently, I was able to experience hospitalization from the other side of the hospital bed. In this short article, I share a few lessons I learned from my own experience and recent experiences with my father and daughter.

Correspondence to: Jay R. Lakhani, MD Marshall University Joan C. Edwards School of Medicine lakhani2@marshall.edu

\section{KEYWORDS}

Empathy

\section{INTRODUCTION}

Could a greater miracle take place than for us to look through each other's eyes for an instant? -Henry David Thoreau

Having been a hospitalist for five years, I often have lost sight of the stress and grief that accompanies hospitalization. Research has shown that caregivers experience significant stress when their children are hospitalized. ${ }^{1}$

The year 2020 started with enormous medical challenges for our family. In January, my father was hospitalized for nearly a week with symptoms related to congestive heart failure. In the next month, my daughter was hospitalized with complications related to a recent tracheal surgery. Finally, I myself became an inpatient after I acquired influenza and developed bilateral pneumonia. These three hospitalizations gave me the opportunity to better understand what it feels like to be on the other side of the hospital bed, to experience what my own patients have been experiencing under my care.
Here are a few things I learned from the other side...

1. I should do a better job of communicating with families. It begins by letting them know when I am coming. Some parents will wait all day to see the doctor, only to step out for ten minutes, and miss everything.

2. I should let people sleep. A hospital is a very difficult place to rest. A patient is constantly being awoken by some new person or new sound. As much as is possible, I will let my patients (and their parents) rest in the mornings. Many have been up with their child through a sleepless night, and my coming back in an hour or two may make a difference for them.

3. I should sit down and listen. Each of my patients may get only a few minutes of my time that day. The least I can do to respect them is to be present while I am there.

4. I should talk about discharge plans every day. What people often want most in the hospital is to go home. Talking about discharge, planning discharge, and hastening discharge (as much as is possible) are daily priorities. 
Empathy in medicine begins when we put ourselves in the place of our patients. Hospitalization produces feelings of fear and uncertainty. The most gifted physicians are those who are able to address both the medical ailments of patients and the psychological comorbidities that accompany the stress of hospitalization. I still have so much to learn when it comes to empathy, but so far, 2020 has given me a good start.

\section{AUTHOR AFFILIATIONS}

1. Marshall University Joan C. Edwards School of Medicine, Huntington, West Virginia

\section{REFERENCES}

1. Commodari E. Children staying in hospital: a research on psychological stress of caregivers. Ital J Pediatr. 2010;36:40. 